\section{Chronic diseases of lifestyle risk factor profiles of a South African rural community}

\author{
Mukadas O. Akindele, Ushotanefe Useh \\ Lifestyle Diseases Niche Area, Faculty of \\ Health Sciences, North West University, \\ Mafikeng Campus, South Africa
}

\begin{abstract}
Globally, chronic diseases of lifestyle account for millions of dollars spent annually on health. These diseases share similar risk factors including: physical inactivity, obesity, cigarette smoking, and hypertension among others. This study sought to assess risk factors for chronic diseases of lifestyle of a rural community in South Africa. This study used a survey design with data randomly collected using the WHO STEPS Instrument for Chronic Disease Risk Factor Surveillance from participants who attended routine checks from February to October 2018 from a trained healthcare practitioner. Informed consent was sought from all participants before the administration of the instrument. The research setting was the community Primary Health Center. About $54.0 \%$ of participants presented with no family history of hypertension but $19.7 \%$ had a family history of type II diabetes mellitus. More women were found to be hypertensive, with the majority (93.4\%) monitoring their blood pressure. The study revealed that more men were current smokers. A large number of participants were engaged in a sedentary lifestyle with about one-third of the participants reported being obese. Physical inactivity, sedentary lifestyle, and hypertension were among the lifestyle-related risk factors for chronic diseases among residents of this rural community.
\end{abstract}

\section{Introduction}

The prevalence of chronic lifestyle diseases is increasing rapidly in rural and urban settings in sub-Saharan Africa. Lifestyle diseases can be defined as noncommunicable diseases that are developed from unhealthy lifestyle practices like inactivity, tobacco smoking, alcohol consumption $^{1}$ and high fat intake are considered as modifiable risk factors. While non-modifiable risk factors are a family history of hypertension, cardiovascular disease, and diabetes mellitus among others. Examples of lifestyle diseases are obesity, cardiovas- cular diseases, certain type of cancers, and diabetes mellitus. $^{2}$

It was reported that, of the 57 million deaths globally in 2008, 63\% of them resulted from non-communicable diseases of cardiovascular diseases, diabetes, cancers, and chronic respiratory diseases. ${ }^{3}$ It was also projected that by the year 2030 , NCDs will account for major causes of death. ${ }^{4}$ Alcohol consumption, tobacco smoking, high blood pressure, and high cholesterol have been reported to be the major causes of disease burden in high and low-income countries. ${ }^{4}$ Variations in the risk factor prevalence and the chronic disease burden have been reported in the literature in different climes. ${ }^{5,6}$ These variations might be due to differences in cultural values, lifestyle, health behaviors engaged in as well as genetic disposition. It is reported that one out of every two United States adults presented with at least one out of the six chronic diseases in 2008 and seven out of ten deaths among Americans died from chronic diseases. $^{7}$

A 2007 study from South Africa reported that high blood pressure, tobacco smoking, alcohol consumption, high body mass index, high cholesterol, diabetes, and physical inactivity were reported to be the common causes of death. ${ }^{8}$ Self-reported hypertension and diabetes were found to be $62.6 \%$ and $11.1 \%$ respectively amongst rural dwellers. These values were higher than that of the urban residents. ${ }^{8}$ Extrapolation of these findings from rural areas might not be applicable in other rural areas $^{2}$ because residents adopt different lifestyles which might influence or interact with a genetic predisposition to either increase or mitigate against chronic disease risk. ${ }^{9,10}$ As part of health information gathering to assist with caring for the person, in the rural areas, this study was conducted to establish the different lifestyle-related chronic diseases in an African rural community as this will assist with health promotion in the reduction of lifestyle-related chronic diseases.

\section{Materials and Methods}

\section{Ethical considerations}

The ethical approval for this study was granted by the North-West University Ethics Committee (NWU-00014-12-A9). All principles of ethics were adhered to. Written informed consent was obtained from each of the participants after thoroughly explaining the details of the study and that participants were free to withdraw from participating at any time without prej-
Correspondence: Mukadas O. Akindele, Lifestyle Diseases Niche Area, Faculty of Health Sciences, North West University, North West University, Mafikeng Campus, South Africa.

Tel.: +27734049785

E-mail:mukaakin@gmail.com

Key words: Lifestyle Diseases; hypertension; tobacco smoking; diabetes; obesity.

Acknowledgements: This work was partially supported by National Research Foundation of South Africa (Grant Number: 99521) by providing funds for MOA during his postdoctoral fellowship. The authors also wish to acknowledge the support of the community leaders, the clinical staff, and everyone who voluntarily enrolled in this study.

Contributions: MOA: The initial conception of the work, design, and data analysis; drafting the manuscript important intellectual content; final approval of the version to be published; accountable for all aspects of the work in line with research integrity. UU: The conception of the initial idea, design, and data analysis; drafting of the manuscript and review of literature; approval of the initial version; takes responsibility for the final product.

Conflict of interest: The authors declare no potential conflict of interest.

Funding: This work was partially supported by the National Research Foundation of South Africa (Grant Number: 99521).

Availability of data and materials: All data generated or analyzed during this study are included in this published article.

Ethics approval and consent to participate: The ethical approval for this study was granted by the North-West University Ethics Committee (NWU-00014-12-A9). The study is conformed with the Helsinki Declaration of 1964, as revised in 2013, concerning human and animal rights.

Informed consent: Written informed consent was obtained from a legally authorized representative(s) for anonymized patient information to be published in this article.

Received for publication: 20 December 2018 Revision received: 24 March 2021.

Accepted for publication: 28 April 2021.

This work is licensed under a Creative Commons Attribution NonCommercial 4.0 License (CC BY-NC 4.0).

${ }^{(C)}$ Copyright: the Author(s),2021

Licensee PAGEPress, Italy

Journal of Public Health in Africa 2021; 12:1006 doi:10.4081/jphia.2021.1006 
udice. The anonymity of participants was ensured as no name or identifiable mark was recorded. The questionnaires were then kept in a safe place which is only accessible to the researcher and the data extracted from the questionnaire was saved in a password-protected laptop.

\section{Study design and population}

A survey design was applied in this study in one of the rural communities of the North West Province, South Africa between February 2018 and October 2018. This community was purposively chosen because of its proximity to the University and a choice for the university's social impact and community engagement activity. The studied community is located at latitude -25.800 and longitude 25.567 (geographical coordinates in decimal degrees) with a population of $2661 \quad(M=1384$, $\mathrm{F}=1278$ ) according to the Census 2011 Statistical release, P0301.4 (Statistics South Africa, 2012). ${ }^{11}$ Participants were recruited through a public announcement in the community by elders and representatives of the village head. All participants completed an informed consent form before participating in the study. Data was obtained from persons who visited the primary health center in the community through a simple random sampling technique. Each participant was instructed by the health worker who assisted in administering the instrument to pick a wrapped paper on which yes or no was written. These wrapped papers were reshuffled before the next participant picked his or hers. Picking yes meant that the participant was chosen to take part while picking no meant no participation. The instrument for data collection consisted of three sections. Section A assessed non-modifiable risk factors while section $\mathrm{B}$ assessed modifiable risk factors. Sections A and B were designed by Diseases of Lifestyle Niche Area, North West University and approved by the Department of Health, North West Province, Republic of South Africa. Section $\mathrm{C}$ assessed the physical activity level of the participants and was adapted from WHO STEPS Instrument for Chronic Disease Risk Factor Surveillance Manual CORE and EXPANDED Physical Activity sections. ${ }^{12}$ The last section of the questionnaire measured Body Mass Index (BMI), Waist Hip Ratio (WHR), and anthropometric variables, and the blood pressure of the participants which were measured by the researcher (MOA). ${ }^{13}$ The questionnaire was self-administered for the participants who were literate and researcher administered for those who were illiterate.

\section{Data analysis}

Statistical Package for Social Sciences (SPSS), version 25 (IBM, Corp., Armonk, New York, United States) was used to analyze data in this study. The descriptive statistics of frequency, percentages and ChiSquare Tests for goodness of fit were used for categorical variables while the t-test was used to determine the differences between parametric variables. For ease of analysis, the age range was categorized into a young adult (aged 18-35 years), middle-aged adult (aged 36-65 years), and older adult (aged $>66$ years). ${ }^{14}$ The body mass index (BMI) of the participants was categorized into underweight $\left(\mathrm{BMI}<18.5 \mathrm{~kg} / \mathrm{m}^{2}\right)$, normal weight $\left(\mathrm{BMI}=18.5-24.9 \mathrm{~kg} / \mathrm{m}^{2}\right)$, overweight $\left(\mathrm{BMI}=25-29.99 \mathrm{~kg} / \mathrm{m}^{2}\right)$ and obese $\left(\mathrm{BMI}>30 \mathrm{~kg} / \mathrm{m}^{2}\right){ }^{13}$ The physical activity level (MET-minute/week) was calculated using this formula:

MET-minutes/week=the sum of the total MET minutes of activity computed for each setting Total Physical

Activity $=[(\mathrm{P} 2 * \mathrm{P} 3 * 8)+(\mathrm{P} 5 * \mathrm{P} 6 * 4)+(\mathrm{P} 8 * \mathrm{P} 9 *$ $4)+(\mathrm{P} 11 * \mathrm{P} 12 * 8)=(\mathrm{P} 14 * \mathrm{P} 15 * 4)]$

The physical activity (PA) levels of the participants were then categorised as follow: high PA (METs $\geq 3000)$, moderate PA (METS $\geq 600$ but less than METs 3000) and low PA (less than METs <600). ${ }^{12}$ Waist hip ratios of the participant are categorized according to gender. MALE: Low CVD risk $(<0.90)$, moderate CVD risk (0.90-0.99), high CVD risk $(\geq 1)$ and FEMALE: Low CVD risk $(<0.80)$, moderate CVD risk (0.80-0.84) and high CVD risk $(\geq 0.85) .{ }^{13}$

\section{Results}

A total of 122 residents of the community participated in this study of which 95 $(77.9 \%)$ were women (Table 1$)$. Fifty percent of the participants (61/122) were within the middle-aged group, and $76.2 \%$ $(93 / 122)$ of all participants were unemployed.

The risk factors for chronic diseases of lifestyle are reported in Table 2. About $54.1 \%(66 / 122)$ of the participants had no family history of hypertension, while $19.7 \%$ (24/122) had a family history of type II diabetes mellitus.

Less than half $(48.4 \% ; 59 / 122)$ of the participants had high METs (Table 3). Women reported higher METs than men. There was however no significant difference by gender $(p=0.78)$. About $25.4 \%$ $(31 / 122)$ of the participants were obese (Table 4). The majority of men reported that they had not done a digital rectal examination for prostate cancer screening. On the contrary, a majority of women reported having done a Pap smear for cervical cancer screening (Table 5).

\section{Discussion}

This study sought to assess the risk factors for lifestyle-related chronic diseases in a rural community of North West Province of South Africa. Less than half of the participants reported to have a family history of hypertension and a few reported family history of stroke, diabetes mellitus, asthma and sudden death with the majority of the respondents who were hypertensive were females. More men were current smokers while the majority of women never smoked

Table 1. Sociodemographic characteristics of participants, South Africa, February 2018 October, 2018.

$\begin{array}{lcc} & \text { No } & \% \\ \text { Gender } & & \\ \text { Male } & 27 & 22.1 \\ \text { Female } & 95 & 77.9 \\ \text { Age* } & & \\ \text { Young Adult } & 50 & 41.0 \\ \text { Middle-aged Adult } & 61 & 50.0 \\ \text { Older Adult } & 11 & 9.0 \\ \text { Educational Status** } & & 30.3 \\ \text { No schooling } & 37 & 25.4 \\ \text { Primary School } & 31 & 44.3 \\ \quad \text { Secondary School } & 54 & 13.9 \\ \text { Occupational Status } & & 76.2 \\ \text { Employed } & 17 & 9.8 \\ \text { Unemployed } & 93 & \\ \text { Pensioner } & 12 & \end{array}$

*Young adult $=$ aged 16-35 years, Middle-aged adult $=$ aged 36-65 years, Older adult $=$ aged 66 and older. **Primary school $=$ grades 1-7, Secondary school $=$ grades $8-12$ 
Table 2. Risk factors for lifestyle-related chronic diseases, South Africa, February 2018-October, 2018.

\begin{tabular}{|c|c|c|c|c|c|c|c|}
\hline \multirow[t]{2}{*}{ Risk factors } & \multicolumn{2}{|c|}{ Men } & \multicolumn{2}{|c|}{ Women } & \multicolumn{2}{|c|}{ All participants } & \multirow[t]{2}{*}{ P-value } \\
\hline & Yes, n (\%) & No, n $(\%)$ & Yes, n (\%) & No, n $(\%)$ & Yes, n (\%) & No, n (\%) & \\
\hline \multicolumn{8}{|l|}{ Family history of non-modifiable factors } \\
\hline Hypertension & $11(19.6)$ & $16(24.2)$ & $45(80.4)$ & $50(75.8)$ & $56(45.9)$ & $66(54.1)$ & 0.66 \\
\hline Stroke & $1(9.1)$ & $26(23.4)$ & $10(90.9)$ & $85(76.6)$ & $11(9)$ & $111(91)$ & 0.45 \\
\hline Diabetes mellitus & $3(12.5)$ & $24(24.5)$ & $21(87.5)$ & $74(75.5)$ & $24(19.7)$ & $98(80.3)$ & 0.28 \\
\hline Asthma & $4(15.4)$ & $23(24.0)$ & $22(84.6)$ & $73(76.0)$ & $26(21.3)$ & $96(78.7)$ & 0.43 \\
\hline Sudden death & $8(23.5)$ & $19(21.6)$ & $26(76.5)$ & $69(78.4)$ & $34(27.9)$ & $88(72.1)$ & 0.81 \\
\hline \multicolumn{8}{|l|}{ Self-reported monitoring of non-modifiable factors } \\
\hline Blood Pressure & $26(22.8)$ & $1(12.5)$ & $88(77.2)$ & $7(87.5)$ & $114(93.4)$ & $8(6.6)$ & 0.68 \\
\hline Diabetes Mellitus & $19(23.8)$ & $8(19.0)$ & $61(76.2)$ & $34(81.0)$ & $80(65.6)$ & $42(34.4$ & 0.65 \\
\hline Cancer & $4(7.3)$ & $23(34.3)$ & $51(92.7)$ & $44(65.7)$ & $55(45.1)$ & $67(54.9)$ & 0.01 \\
\hline \multicolumn{8}{|l|}{ Self-reported personal history of non-modifiable factors } \\
\hline Hypertension & $4(10.0)$ & $23(28.0)$ & $36(90.0)$ & $59(72.0)$ & $40(32.8)$ & $82(67.2)$ & $0.04^{*}$ \\
\hline Diabetes mellitus & $2(28.6)$ & $25(21.7)$ & $5(71.4)$ & $90(78.3)$ & $7(5.7)$ & $115(94.3)$ & 0.65 \\
\hline Asthma & $2(50.0)$ & $25(21.2)$ & $2(50.0)$ & $93(78.8)$ & $4(3.3)$ & $118(96.7)$ & 0.21 \\
\hline Modifiable factors & \multicolumn{2}{|c|}{ Current } & \multicolumn{2}{|c|}{ Stopped } & \multicolumn{2}{|c|}{ Never } & \\
\hline Smoking & $10(52.6)$ & $9(47.4)$ & $5(41.7)$ & $7(58.3)$ & $12(13.2)$ & 79 (86.8) & \\
\hline Alcohol drinking & $13(39.4)$ & 20 (21.1) & $1(50.0)$ & $1(50.0)$ & $13(14.9)$ & $74(85.1)$ & \\
\hline
\end{tabular}

Table 3. Physical activity and sedentary levels of participants, South Africa, February 2018-October 2018.

\begin{tabular}{|c|c|c|c|c|}
\hline & Men, n (\%) & Women, n (\%) & Total, n (\%) & P-value \\
\hline $\begin{array}{l}\text { METS* } \\
\text { Low METs } \\
\text { Moderate METs } \\
\text { High METs }\end{array}$ & $\begin{array}{c}3(2.5) \\
4(3.3) \\
20(16.4)\end{array}$ & $\begin{array}{l}31(25.4) \\
25(20.5) \\
39(32.0)\end{array}$ & $\begin{array}{l}34(27.9) \\
29(23.8) \\
59(48.4)\end{array}$ & $<0.001$ \\
\hline $\begin{array}{l}\text { Sedentary Level } \\
\text { High Sedentary level } \\
\text { Low Sedentary level }\end{array}$ & $\begin{array}{c}0(00.0) \\
27(22.1)\end{array}$ & $\begin{array}{c}1(0.8) \\
94(77.0)\end{array}$ & $\begin{array}{c}1(0.8) \\
121(99.2)\end{array}$ & 0.78 \\
\hline
\end{tabular}

${ }^{\circ}$ Chi-Square Tests for goodness of fit. *METs=metabolic equivalent per second (High PA=METs $\geq 3000$, Moderate PA=METS 2600 but less than METs 3000, Low PA less than METs $<600$

Table 4. Body adiposity classification of participants, South Africa, February 2018-October 2018.

\begin{tabular}{lccc} 
Adiposity classifications & Men, $\mathbf{n}(\%)$ & Women, $\mathbf{n}(\%)$ & Total, n (\%) \\
Body Mass Index* & & & $17(13.9)$ \\
$\quad$ Underweight & $7(5.7)$ & $10(8.2)$ & $47(38.5)$ \\
$\quad$ Normal weight & $13(10.7)$ & $34(27.9)$ & $27(22.1)$ \\
Overweight & $7(5.7)$ & $20(16.4)$ & $31(25.4)$ \\
$\quad$ Obese & $0(0.0)$ & $31(25.4)$ & $6(4.92)$ \\
Waist-to-hip ratio** & $3(11.1)$ & $3(3.2)$ & $2(1.64)$ \\
Low risk & $1(3.7)$ & $1(1.1)$ & $114(93.44)$ \\
Moderate risk & $23(85.2)$ & $91(95.8)$ & \\
High risk & & & \\
\hline
\end{tabular}

*Underweight $\left(\mathrm{BMI}<18.5 \mathrm{~kg} / \mathrm{m}^{2}\right)$, Normal weight $\left(\mathrm{BMI}=18.5-24.9 \mathrm{~kg} / \mathrm{m}^{2}\right)$, Overweight $(\mathrm{BMI}=25-29.99 \mathrm{~kg} / \mathrm{m} 2)$, Obese $\left(\mathrm{BMI}>30 \mathrm{~kg} / \mathrm{m}^{2}\right)$. ${ }^{* *}$ MALE: Low CVD risk $(<0.90)$, moderate CVD risk $(0.90-0.99)$, high CVD risk $(\geq 1)$. FEMALE: Low CVD risk ( $<0.80)$, moderate CVD risk (0.80-0.84) and high CVD risk ( $\geq 0.85)$.

Table 5. Participants' cancer screenings, South Africa, February 2018-October 2018.

\begin{tabular}{|c|c|c|c|c|}
\hline & & & & \\
\hline & Yes, n (\%) & No, in (\%) & Yes, n (\%) & No, n (\%) \\
\hline Digital rectal exam & $2(7.4)$ & $25(92.6)$ & & \\
\hline Pap smear & & & $60(63.2)$ & $35(36.8)$ \\
\hline Acetic acid wash & & & $0(0.0)$ & $95(100)$ \\
\hline Clinical breast exam & & & $1(1.1)$ & $94(98.9)$ \\
\hline
\end{tabular}


and less than half of the participants had high METs of which majority of them were females while a large number of the participants engaged in low sedentary lifestyle of which were more females.

\section{Hypertension as a risk factor}

Most of the participants were found to be hypertensive with less than half of the participants reporting familial history of hypertension, stroke, diabetes mellitus, asthma, and sudden death. One of the important non-modifiable risk factors for high blood pressure is a family history of hypertension. The majority of the participants reported a family history of hypertension with more than one-third of them also being hypertensive. The finding of this study is supported a 2015 study conducted in Sri Lanka which reported high prevalence of hypertension among Sri Lankan adults with a family history of hypertension and that the family history of hypertension is associated with the prevalence of obesity, central obesity, and metabolic syndrome. ${ }^{15}$ Other researchers also documented family history of hypertension as one of the major risk factors for hypertension later in life 16,17 and those healthy non-obese men with both parents who are hypertensive were reported to have higher daytime and night-time ambulatory high blood pressure than men with parents who were not hypertensive. ${ }^{18}$

Among the modifiable risk factors assessed and reported by the participants were hypertension, diabetes mellitus, and asthma. Hypertension was ranked as second among the selected risk factors attributing to deaths among South Africans in an earlier study. ${ }^{19}$ High blood pressure was mostly reported by South African respondents in a study to assess lifestyle related chronic diseases. ${ }^{18}$ This agrees with the outcome of this work. ${ }^{20}$ A $20.1 \%$ prevalence of selfreported hypertension was reported in rural areas of Brazil in 2013, which was lower than the prevalence observed in this present study. ${ }^{21}$ The difference in the prevalence might be a result of many factors; in this study only one rural community was surveyed, unlike the 2013 study in Brazil, ${ }^{21}$ where data was collected in many rural communities in Brazil. ${ }^{22}$

\section{Diabetes mellitus as a risk factor}

One out of every twenty residents selfreported diabetes mellitus. The low prevalence reported in this paper is at variance with that reported of the Anganwadi areas of Kerala, India, ${ }^{23}$ and among individuals from a lower socioeconomic group in Trinidad and Tobago. ${ }^{24}$ On the contrary, a 2015 study reported a low prevalence of self-reported diabetes mellitus among the employees of Aligarh Muslim University, Aligarh, India. ${ }^{25}$ The reasons for the differences in levels of prevalence is not documented, but might be related to the socioeconomic status and different dietary patterns of participants.

\section{Asthma}

The prevalence of self-report asthma in the study was low. This result is similar to that found among Bangladeshi adults residing in rural area, ${ }^{26}$ and South Africa, Tanzania, Cameroon, and Nigeria. ${ }^{27-30}$ The reason for the low prevalence reported in this study by participants is not known; therefore, further study to investigate the reasons are suggested.

\section{Cigarette smoking as a risk}

Cigarette smoking was one of the modifiable risk factors investigated in this study. About one-third of the participants were either currently smoking or had smoked. Cigarette smoking had been reported to increase the risk of stroke and caused about 4.8 million adult deaths globally in $2000 .^{31}$ A study in India from $2013^{32}$ reported that smoking and alcohol as risk factors for chronic diseases of lifestyle with a prevalence of $45.4 \%$ and alcohol intake of $41.8 \%$ among patients visiting rural tertiary care hospital, while lower risk factor prevalence of $39 \%$ and $27 \%$ were reported for smoking and alcohol consumption respectively among the slum urban dwellers in Coimbatore, Tamil Nadu, India. ${ }^{33}$ Earlier on, a 2000 study in South Africa found that between $12-15 \%$ of deaths were caused by tobacco smoking among adults. ${ }^{34}$ Furthermore, tobacco smoking ranked third among risk factors for chronic diseases of lifestyle among South Africans in three rural towns of Free State. ${ }^{35}$

\section{Physical inactivity, excess body weight, sedentary lifestyle, and high WHR}

Physical inactivity, excess body weight, sedentary lifestyle, and high WHR are all risk factors of chronic diseases of lifestyle. ${ }^{36}$ It was found in this study that more than half of the participants had low/ moderate physical activity levels. This is similar to the findings of a 2011 study in Canada that reported that 1 in 5 people are physically inactive. ${ }^{36}$ The need to be physically active had been discussed extensively in the literature. ${ }^{36}$ Physical inactivity leads to premature aging, obesity, depression, susceptibility to cardiovascular diseases, and musculoskeletal demineralisation (disuse syndrome). ${ }^{37}$ However, engaging in light, moderate, or vigorous physical activi- ty is a panacea to cardiovascular disease mortality irrespective of the presence of metabolic risk factors in individuals. ${ }^{38}$ Physical inactivity was found to accelerate the aging process among the white twin volunteers. ${ }^{39}$

Assessment of the participants' body adiposity shows that about one-third of our participants were obese. Similar findings have been reported among the rural dwellers of Pune, India and a rural Han Chinese population. ${ }^{40-42}$ The increase in the BMI and WHR amongst participants might be due to the embracing urban lifestyles by this community.

\section{Cancer}

Interestingly, the majority of the female participants screened themselves for cervical cancer using Pap smear while very few male participants screened for prostate cancer using the digital rectal examination. The high number in the cervical cancer screening observed in our study might be due to the high level of community/public health education by the Provincial Department of Health and health seeking behavior as influenced by gender. Cancer is reported as one of the NCDs ravaging persons from both high and low-income countries especially sub-Saharan Africa; cervical cancer is reported to be common in African women, ${ }^{43}$ This is preventable and WHO recommends screening for women of 30 years and above. ${ }^{44}$ An overall prevalence of $0-53.6 \%$ screening uptake was reported in a scoping review in sub-Saharan Africa, ${ }^{45}$ while $14.3 \%$ and $7.1 \%$ of Indian urban residents reported a lifetime pelvic examination and cervical screening respectively. ${ }^{46}$ Very low number of male participated in this study and findings can therefore not be generalizable. A 2016 study in Jamaica also reported a low number $(n=180)$ as the mean of the screened Jamaicans per calendar year between 1996 and 2005 with a peak of 300 men in the year 1999. ${ }^{47}$ Men of African descent have also been reported to less likely to subject themselves to prostate cancer screening when compared to men from other racial extractions..$^{48,49}$ Healthcare providers need to come up with public health strategies to manage the prevalence of cancers among sub-Saharan Africans.

\section{Limitations}

The outcome of the study should be interpreted with caution because the researchers had limited control over the responses of the participants especially on questions regarding their physical activity levels, METs, and sedentary lifestyles. This work serves as baseline for studies within rural communities in South Africa because 
no study had addressed NCDs in rural communities within this Province. An intervention study should be therefore be designed with consideration for the norms and culture of this and other communities. It is highly suggested that this study should assist community health workers in the campaign of reducing risk factors of chronic diseases of lifestyle in rural African communities.

\section{Conclusions}

The study examined the risk factors for chronic diseases of lifestyle among rural community dwellers of a community in North West Province of South Africa. The outcome of this study showed that few participants reported a family history of high blood pressure, sudden death, and type II diabetes mellitus, and that cigarette smoking and alcohol consumption were among the modifiable risk factors for CDLs. The majority of our female participants screened themselves for cervical cancer while few male participants underwent prostate cancer using the digital rectal examination.

\section{References}

1. Australian Institute of Health and Welfare. Australia's Health 2014. Canberra: AIHW; 2014.

2. van Zyl S, van der Merwe LJ, Walsh $\mathrm{CM}$, et al. Risk-factor profiles for chronic diseases of lifestyle and metabolic syndrome in an urban and rural setting in South Africa. Afr J Prm Health Care Fam Med 2012;4:346.

3. Alwan A. Global status report on noncommunicable diseases 2010. Geneva, Switzerland: WHO; 2011:176.

4. Ezzati M, Lopez AD, Rodgers A, et al. Comparative risk assessment collaborating group. Selected major risk factors and global and regional burden of disease. Lancet 2002;360:1347-60.

5. Murray CJ, Vos T, Lozano R, et al. Disability-adjusted life years (DALYs) for 291 diseases and injuries in 21 regions, 1990-2010: a systematic analysis for the Global Burden of Disease Study 2010. Lancet 2012;380:2197-23.

6. World Health Organization. Global Status Report on non-communicable diseases: Attaining the nine global noncommunicable diseases targets; a shared responsibility Geneva, Switzerland: World Health Organization; 2014.

7. Centers for Disease Control and
Prevention (CDC). Chronic diseases and health promotion, 2012. Accessed: 18th November, 2018. Available from: https:/www.cdc.gov/chronicdisease/in dex.htm

8. Norman R, Bradshaw D, Schneider M, et al. A comparative risk assessment for South Africa in 2000: Towards promoting health and preventing disease. SAMJ 2007;97:637-41.

9. Anand SS. The value of studying geneenvironment interactions in culturally diverse populations. Can J Physiol Pharmacol 2005;83:42-6.

10. Bolli P. The question of the role of ethnicity on cardiovascular risk: does it matter where we come from? J Hypertens 2005;23:1331- 3 .

11. Census 2011 Statistical release P0301.4 / Statistics South Africa. Pretoria: Statistics South Africa, 2012. Accessed 18th November, 2018.

12. WHO STEPS Surveillance Manual: The WHO STEPwise Approach to Chronic Disease Risk Factor Surveillance. Geneva, Switzerland: World Health Organisation; 2008.

13. Ul-Haq Z, Smith DJ, Nicholl BI, et al. Gender differences in the association between adiposity and probable major depression: a cross-sectional study of 140,564 UK Biobank participants. BMC Psychiatry 2014;14:153.

14. Petry NM. A comparison of young, middle-aged and older adult treatmentseeking pathological gamblers. Gerontologist 2002;42:90-9.

15. Ranasinghe P, Cooray DN, Jayawardena R, Katulanda P. The influence of family history of hypertension on disease prevalence and associated metabolic risk factors among Sri Lankan adults. BMC Public Health 2015; 15:576.

16. Lauer RM, Burns TL, Clarke WR, Mahoney LT. Childhood predictors of future blood pressure. Hypertension 1991;18:I74-81.

17. Williams RR, Hunt SC, Hasstedt SJ, et al. Are there interactions and relations between genetic and environmental factors predisposing to high blood pressure? Hypertension 1991;18:I29- 37.

18. Goldstein IB, Shapiro D, Guthrie D. Ambulatory blood pressure and family history of hypertension in healthy men and women. Am J Hypertens 2006;19:486-91.

19. Norman R, Bradshaw D, Schneider M, et al. A comparative risk assessment for South Africa in 2000: towards promoting health and preventing disease. S Afr Med J 2007;97:637-41.

20. Centre of Health Systems Research and
Development. The rapid assessment on compliant behaviour of people (18 years and older) with diagnosed noncommunicable chronic diseases. Pretoria: Department of Health; 2004.

21. Moreira JP, Moraes JR, Luiz RR. Prevalence of self-reported systemic arterial hypertension in urban and rural environments in Brazil: a populationbased study. Cad Saud Publica 2013;29:62-72.

22. Fang J, Gillespie C, Ayala C, Loustalot F. Prevalence of self-reported hypertension and antihypertensive medication use among adults aged $>18$ yearsUnited States, 2011-2015. MMWR Morb Mortal Wkly Rep 2018;67:21924.

23. Tiwari RR, Deb PK, Debbarma A, et al. Risk factors analysis in self-reported diabetes in a rural Kerala population. Int J Diabetes Dev Cities 2008;28:91-4.

24. Chadee D, Seemungal T, Pereira LXM, et al. Prevalence of self-reported diabetes, hypertension and heart disease in individuals seeking State funding in Trinidad and Tobago, West Indies. J Epidemiol Glob Health 2013;3:95-103.

25. Khan MS, Khan Z. Amir A. Prevalence of self-reported diabetes mellitus in an urban population. Int J Med Sci Public Health 2015;4:1369-72.

26. Barlett E, Parr J, Lindeboom W, et al. Sources and prevalence of self-reported asthma diagnosis in adults in urban and rural settings of Bangladesh. Glob Public Health, 2013;8:79-89.

27. Ehrlich RI, White N, Norman R, et al. Wheeze, asthma diagnosis and medication use: A national adult survey in a developing country. Thorax 2005;60:895-901.

28. Mugusi F, Edwards R, Hayes L, et al. Prevalence of wheeze and self-reported asthma and asthma care in an urban and rural area of Tanzania and Cameroon. Trop Doct 2004;34:209-14.

29. Pefura-Yone EW, Kengne AP, Balkissou AD, et al. Research group for respiratory disease in Cameroon. Prevalence of asthma and allergic rhinitis among adults in Yaounde, Cameroon. PLoS ONE 2015;10:e0123099.

30. Desalu OO, Oluboyo PO, Salami AK. The prevalence of bronchial asthma among adults in Ilorin, Nigeria. Afr J Med Med Sci 2009;38:149-54.

31. Ezzati M, Lopez AD, Rodgers A, Murray CJL (eds.). Comparative quantification of health risks: Global and regional burden of disease attributable to selected major risk factors. Vol 1, Chapter 11. Geneva: WHO; 2004:497- 
596.

32. Prasanna D, Rajesh V, Satish Kumar BP, et al. Assessment of lifestyle-related risk factors contributing for chronic non-communicable disease in patients visiting rural tertiary care hospital. Int Res J Pharm 2013;4.

33. Nandini SH, Karthikeyan S. An educational intervention on the risk factors of lifestyle diseases among men aged 3050 years in an urban slum in Coimbatore, Tamil Nadu, India. Int $\mathrm{J}$ Community Med Public Health 2017;4:181-5.

34. Groenewald P, Vos T, Norman R, et al. Estimating the burden of disease attributable to smoking in South Africa in 2000. S Afr Med J 2007;97:674-81.

35. van Zyl S, van der Merwe LJ, Walsh $\mathrm{CM}$, et al. A risk-factors profile for chronic lifestyle diseases in three rural Free State towns. SA Fam Pract 2010;52:72-6.

36. Dumith SC, Hallal PC, Reis RS, Kohl HW 3rd. Worldwide prevalence of physical inactivity and its association with human development index in 76 countries. Prev Med 2011;53:24-8.

37. Bortz WM II. The disuse syndrome. West J Med 1984;141:691-4.

38. Reddigan JI, Ardern CI, Riddell MC,
Kuk JL. Relation of physical activity to cardiovascular disease mortality and the influence of cardiometabolic risk factors. Am J Cardiol 2011;108:1426-31.

39. Cherkas LF, Hunkin JL, Kato BS, et al. The association between physical activity in leisure time and leukocyte telomere length. Arch Intern Med 2008;168:154-8.

40. Rathi, MA, Irani A, Kakrani VA. Obesity and its risk factors in urban and rural females of Pune. IOSR J Nursing Health Sci 2014;3:24-8.

41. Jin MJ, Chen BB, Mao YY, et al. Prevalence of overweight and obesity and their associations with socioeconomic status in a rural Han Chinese adult population. PLoS ONE 2013;8:e79946.

42. $\mathrm{Hu} \mathrm{L}$, Huang $\mathrm{X}$, You C, et al. Prevalence of overweight, obesity, abdominal obesity and obesity-related risk factors in southern China. PLoS ONE 2017; 12:e0183934.

43. De Vuyst H, Alemany L, Lacey C, et al. The burden of human papillomavirus infections and related diseases in subSaharan Africa. Vaccine 2013;31:F3246

44. World Health Organization. Guidelines for screening and treatment of precan- cerous lesions for cervical cancer prevention. Geneva: WHO; 2013.

45. Lott BE, Trejo MJ, Baum C, et al. Interventions to increase uptake of cervical screening in sub-Saharan Africa: a scoping review using the integrated behavioral model. BMC Public Health 2020;20:654.

46. Reichheld A, Mukherjee PK, Rahman SM, et al. Prevalence of cervical cancer screening and awareness among women in an urban community in south IndiaA cross sectional study. Ann Global Health 2020;86:30.

47. Morrison BF, Aiken W, Mayhew R, et al. Prostate cancer screening in Jamaica: Results of the largest national screening clinic. J Cancer Epidemiol 2016;2016:2606805.

48. Gilligan T, Wang PS, Levin R, et al. Racial differences in screening for prostate cancer in the elderly. Arch Intern Med 2004;164:1858-64.

49. Consedine NS, Morgenstern AH, Kudadjie-Gyamfi E, et al. Prostate cancer screening behavior in men from seven ethnic groups: the fear factor. Cancer Epidemiol Biomarkers Prev 2006;15:228-37. 